\title{
An Investigation on Strength Degradation of Gfrp Laminates Under Environmental Impact
}

\author{
P. Sampath Rao ${ }^{1}$, M. Manzoor Husain ${ }^{2}$, D. V. Ravi Shankar ${ }^{3}$ \\ ${ }^{1}$ Research scholar JNT University Hyderabad. Mechanical Engineering Department Vijay Rural Eng. College, Nizamabad A.P.India \\ ${ }^{2}$ Mechanical Engineering Department JNT University Hy derabad. A.P.India \\ ${ }^{3}$ Nizam Institute of Engineering and Technology, Hyderabad. A.P. India
}

\begin{abstract}
The usage and replacement of conventional materials with polymer composite materials for engineering applications is always questioned by the end user, unless otherwise supported by the authentic published research. The reinforcement materials are highly hygroscopic; the matrix material provides protection to the reinforcement. Since the edges of composite components and surface are exposed to environment, water molecules travel along the reinforcement, which can damage the interfacial bonding, further the performance of the composite laminate may get affected. In this scenario the investigation related to this aspect, requires quantitative assessment which is carried out to estimate the damage associated by accelerated simu lation of the real time situation provides information to extrapolate the effects of the mo isture associated damage to the composite laminate. In this present work an attempt has been made in establishing the investigation procedure to estimate the influence of mo isture absorption on strength degradation coupled with temperature. To estimate the life cycle time of polymer composite components such as marine boats and components related to submarine applications. From the test results, it is established reduced that the tensile strength and flexural modulus were reduced significantly, of the specimens subjected to water soaking and varying temperature.
\end{abstract}

Keywords Glass Fibre Reinforced Polymer Composite (GFRP), Resin Transfer Moulding (RTM), Tensile and Bending Test

\section{Introduction}

Glass fibre reinforced plastic materials are of low cost, light in weight, have good mechanical properties thus having potential to use them for structural applications such as equipment for chemical plants and pipelines which are subjected to aggressive environment. Therefore, the information comprising the effects of moisture absorption at higher temperatures on the mechanical properties of glass reinforced composites is very essential. Glass fibre reinforced poly mer composites (GFRP) show relatively low degradation in various corrosive environments in the unstressed state, however, they are very susceptible to stress corrosion, especially in dilute mineral acid environment[1,2]. Krystyna Imielinska discussed in detail about the environmental stress cracking characteristics of GFRP and (A-G) FRP which were studied using CT (fracture mechanics) samples under.

Constant tensile load and water environment. For GFRP the characteristics of crack length as a function exposure

* Corresponding author:

sampathrao_polusani@yahoo.co.in (P. Sampath Rao)

Published online at http://journal.sapub.org/cmaterials

Copyright (C) 2012 Scientific \& Academic Publishing. All Rights Reserved time (upto3 months).Ductile aramid fibres seemed to protect the glass fibre reinforcement from stress cracking due to higher chemical resistance and complex failure mechanis ms [3].Accelerated environmental ageing study of polyester/glass fibre reinforced composites (GFRPCs) were studied based on two kinds of alternating cycles, which provided humidity, temperature and ultraviolet radiation The study dynamic mechanical analysis, for a range of temperatures and frequencies under tensile and three-point bending loadings, revealed that the aged materials gained in stiffness, whereas a small deterioration in strength was found[6] Tensile and flexural strength of bamboo fibre reinforced polypropylene composite and bamboo-glass fibre reinforced polypropylene hybrid composite were reduced[8]. On similar way experimental work has been done with polyester-glass fibre reinforced composites. The environmental stress cracking failure due to temperature and moisture has been studied for glass fibre reinforced composites [9]. Moisture does not only affect the adhesive bond of the bonded system in service, but also during the application of FRP on concrete surface. Tests on CFRP bonded to concrete with initially damp surface using a modified cantilever beam indicated reduction in bond strength when compared to specimens with initially dry concrete surface[11]. Since the failure under effect of mo isture generally occurs by either concrete delaminating 
or concrete-epoxy interface separation. The effects of variable mo isture conditions on the fracture toughness of concrete/FRP bonded system are studied by means of the peel and shear fracture toughness determined from the conditioned test specimens. Moisture conditions can result in strength degradation[13].The main objective of this work is to investigate the effects of hydro aging and hydrothermal aging environmental (constant temperature water bath) conditions on the performance and durability of glass fibre reinforced polymer.

\section{Experimental Setup}

\subsection{Prepar ation of Test Samples}

The specimens for the present work are prepared using RTM Machine. The specifications for the laminate preparation are (i) injection pressures, $30-40$ psi. (ii) Curing Temperature - room temperature. The laminates obtained by RTM is the size $300 \mathrm{~mm} \times 300 \mathrm{~mm} \times 8 \mathrm{~mm}$. These laminates are sliced to standard ASTMD 638 tensile specimens of dimensions $250 \mathrm{~mm} \times 30 \mathrm{~mm} \times 8 \mathrm{~mm}$ (as shown fig.1). These Specimens are immersed in the water bath at room temperature for a period of 180days and other set of specimens immersed inconstant temperature water bath which is maintained at $60^{\circ} \mathrm{C}$ for a period of 60days (as shown fig.2\&3).

\section{Specifications of materials used in the composite} laminate:

Matrix: General purpose polyester resin (commercial Grade)

Glass fibre: Saint Gobain makes

$$
\text { E-Glas s }
$$

Chopped strand mat (stitched) $450 \mathrm{~g} / \mathrm{s}-\mathrm{m}$, the laminates are prepared with RTM process. The volume fraction of the reinforcement loading about $40 \%$ which is found by Burn test the remaining is matrix About $60 \%$

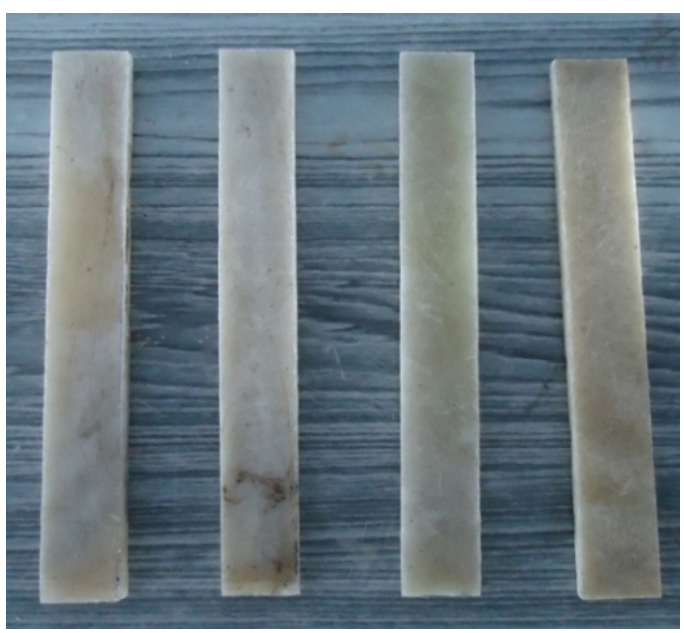

Figure 1. pieces of laminate produced

Specimen size: Specimen Length $=250 \mathrm{~mm}$ Specimen Gauge Length for tensile test $200 \mathrm{~mm}$ and bending test
$220 \mathrm{~mm}$, Width $\mathrm{b}=30 \mathrm{~mm}$, Depth or Thickness $\mathrm{d}=8 \mathrm{~mm}$

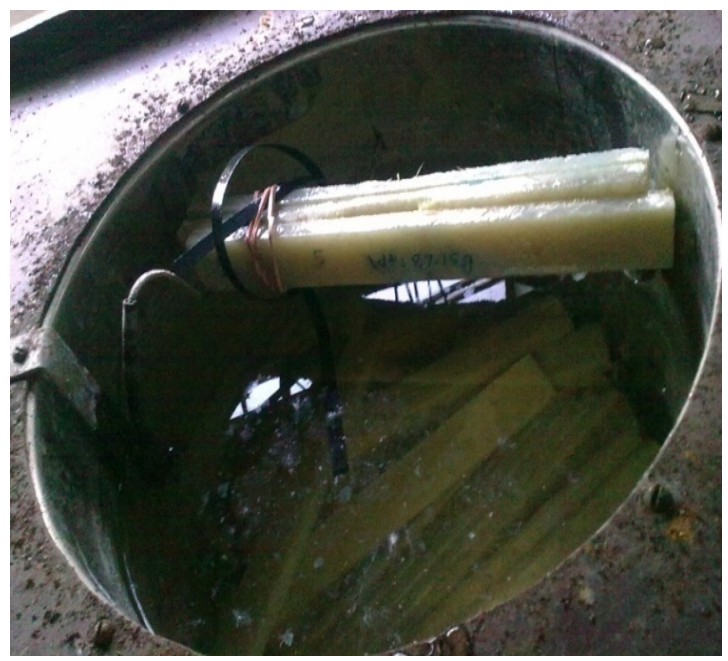

Figure 2. Specimens in water bath at room temperature

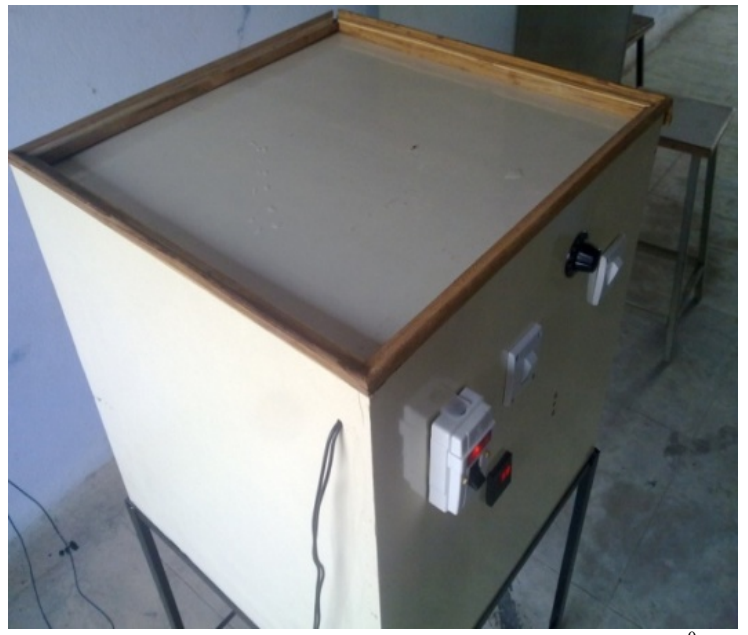

Figure 3. Constant temperat ure water bath maintained at $60^{\circ} \mathrm{C}$

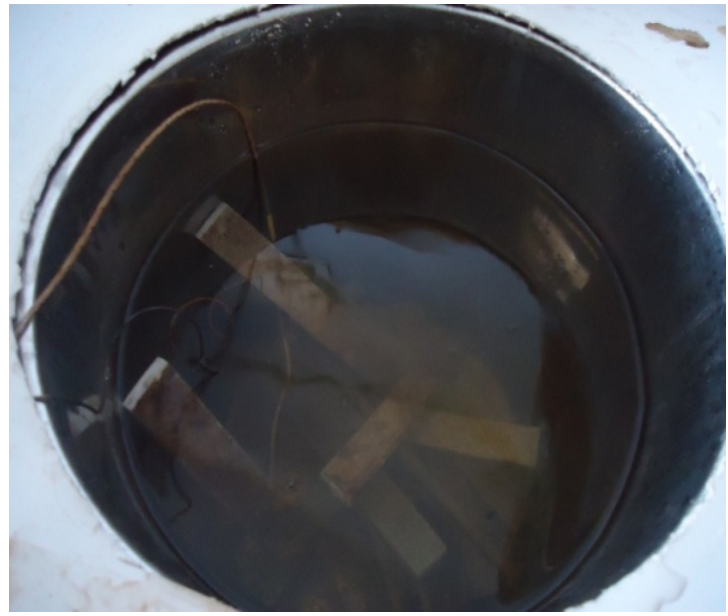

Figure 4. Constant temperature water bath with specimens

\subsection{Experimentation}

The present work is focused to understand influence of the water soaking time which leads to reduce GFRP composite laminate's tensile strength. The experiments were carried out on number of specimens moulded by 
RTM and exposed to water bath which is maintained at room temperature and constant temperature at $60^{\circ} \mathrm{C}$. Every 30 days specimens are taken from bath which are exposed to room temperature and for every 10 days specimens are taken from bath which is maintained at $60^{\circ} \mathrm{C}$ temperature, and carried out tensile tests, 3-point bending tests to determine the young's and flexural modulus which are exposed to various periods.

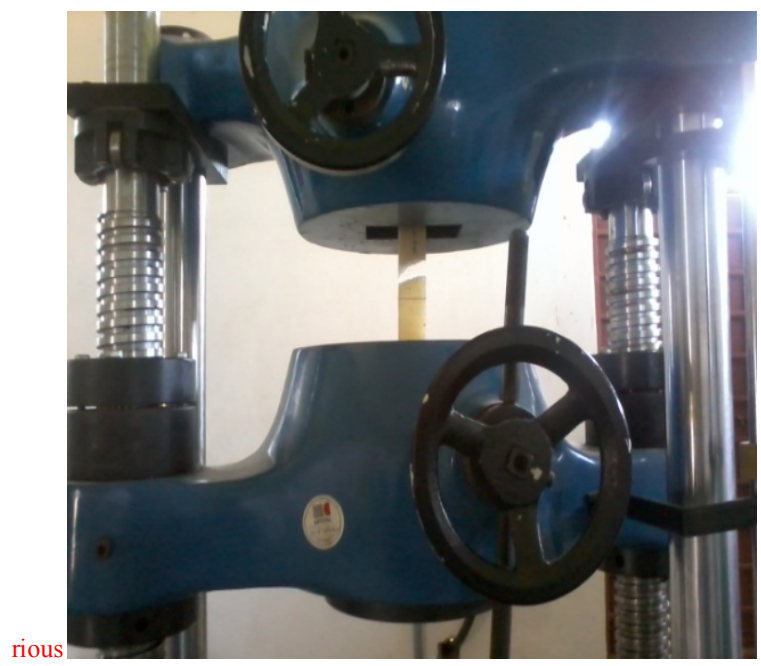

Figure 5. Tensiletesting on UTM

\section{Results-Tensile and Flexural Modulus}

The laminates are exposed to water bath at room temperature, and are tested with tensile and 3-point bending test. This is repeated for every 30 days, the results are noted and the same displayed in $\mathrm{graphs} 1 \& 3$.The laminates are exposed at constant temperature $60^{\circ} \mathrm{C}$, tested with tensile and 3-point bending test. This is repeated for every 10 days, and plotted graphs $2 \& 4$ with the obtained results. From stress-strain graphs tensile young's modulus of the specimens are calculated with in the elastic limits choosing three points in a straight line portion and shown in graphs5and6. The specimen exposed for $60^{\circ} \mathrm{C}$ for 10 days tensile modulus is calculated as

Young's Modulus (10 Days),

$$
\begin{aligned}
\mathbf{E}_{1} & =(8 / 0.7+10 / 0.9+10.5 / 1) / 3 * 100 \mathrm{~N} / \mathrm{mm}^{2} \\
& =1.101 \mathrm{Gpa}
\end{aligned}
$$

Flexural modulus of elasticity is calculated with graphs 3 and 4 for specimens exposed at room temperature and constant temperature $60^{\circ} \mathrm{C}$ with defferent exposure times by using following equation and the results are shown in graphs 5and 6 .

$$
E_{f}=\frac{L^{3} m}{4 b d^{3}}
$$

$L=$ Support span (laminate length), (mm)

$\mathrm{M}=$ slope of the deflection curve in initial straight portion $(\mathrm{N} / \mathrm{mm})$

$$
b=\text { Width of test beam, (mm) }
$$

$d=$ Depth of tested beam, $(\mathrm{mm})$

The specimen exposed at room temperature for 180days flexural modulus is calculated as

$$
\begin{aligned}
E_{f 1} & =\mathrm{L}^{3} * \mathrm{M} / 4 \mathrm{bd}^{3} \\
E_{f 1} & =220^{3} * 0.0333 * 10^{3} / 4 * 30 * 8^{3} \\
& =5.7764 \mathrm{Gpa}
\end{aligned}
$$

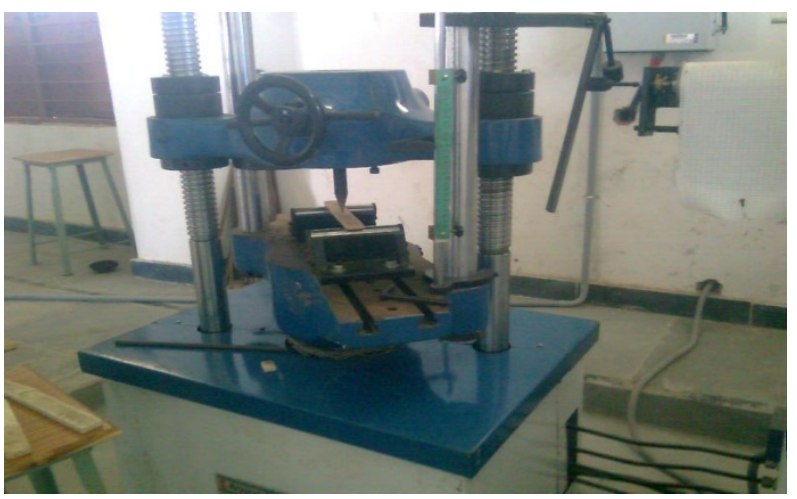

Figure 6. Three point bending testing on UTM

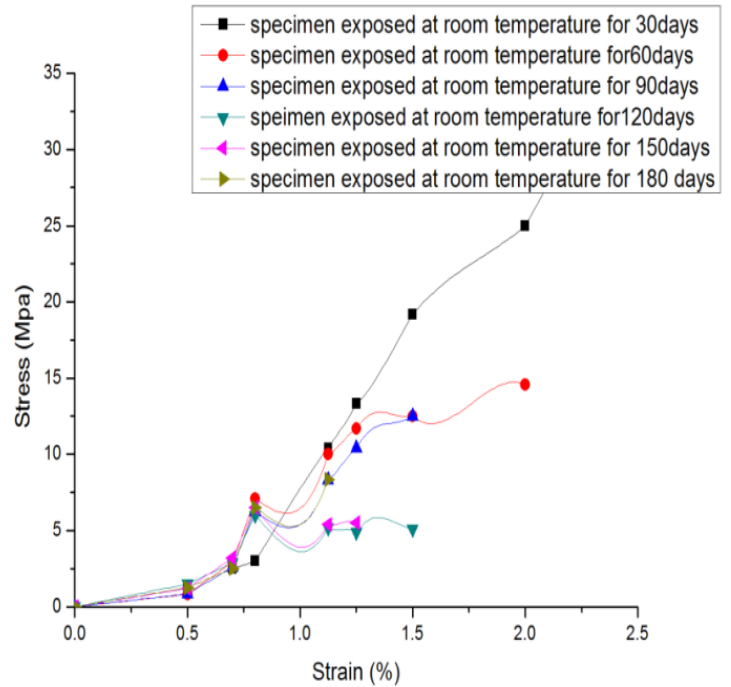

Graph 1. Tensiletest-specimens exposed to room temperature (stress V/S Strain at various exposed time 30 to180days)

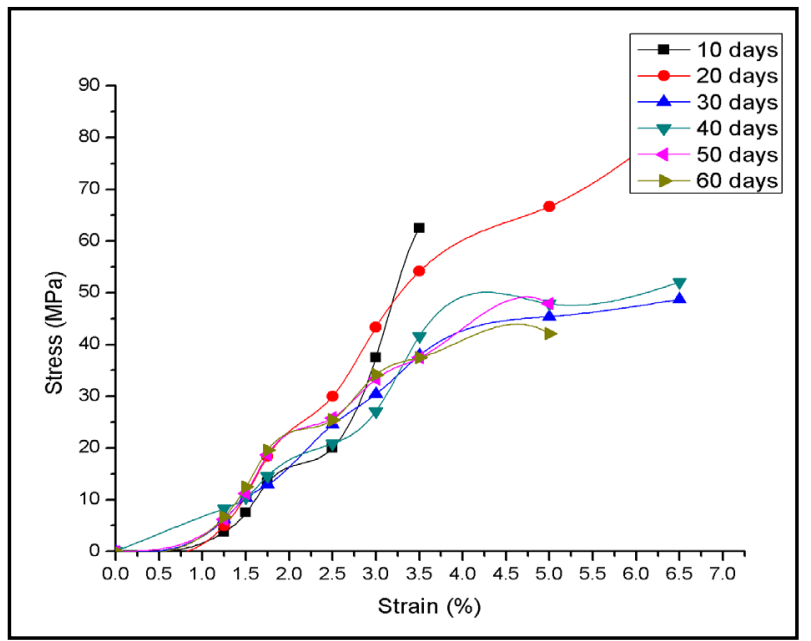

Graph 2. Tensile test-Specimen exposed to constant temperature $600 \mathrm{C}$ (stress V/s Strain at various exposed time 10 to 60 days) 


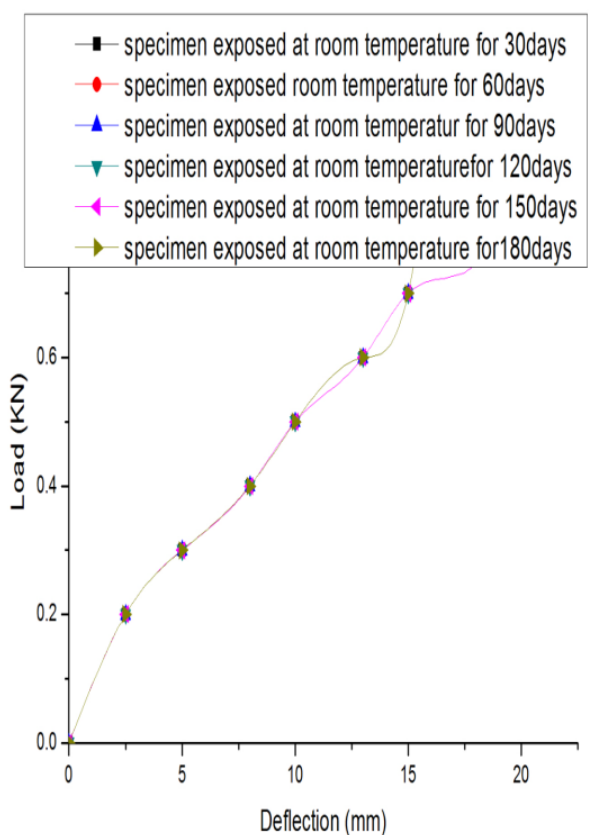

Graph 3. Three point bending test-Specimen exposed at room temperat ure (Loadv/s Deflection exposed time 30 to 180days)

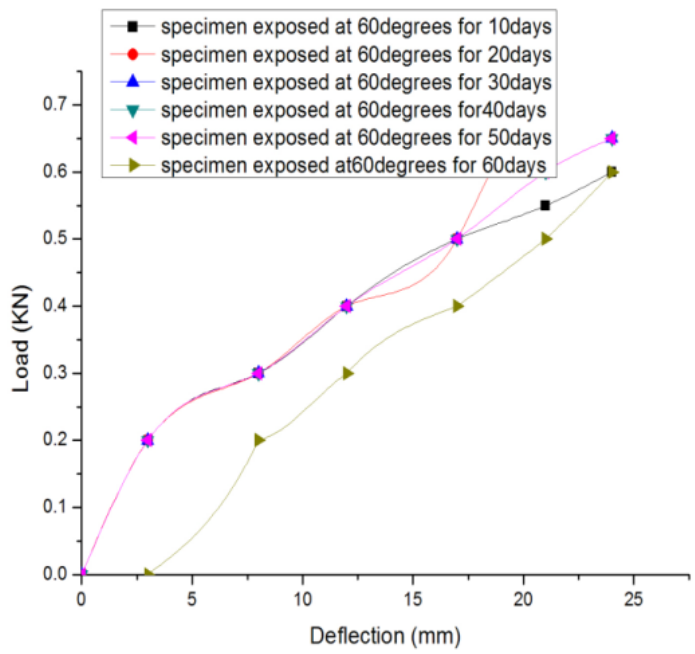

Graph 4. Three point bending test-Specimen exposed at temperature 60 degrees (Load $\mathrm{v} / \mathrm{s}$ deflection exposed time 10 to 60 days)

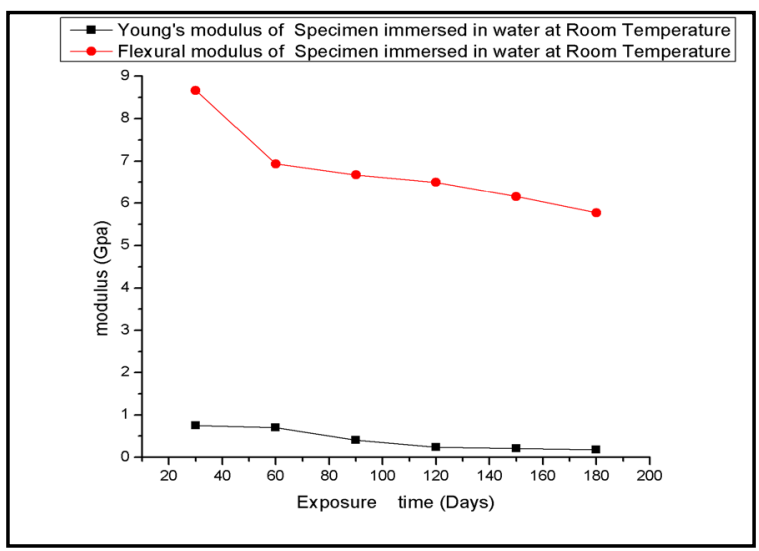

Graph 5. Modulus v/s Exposure time at room Temperature

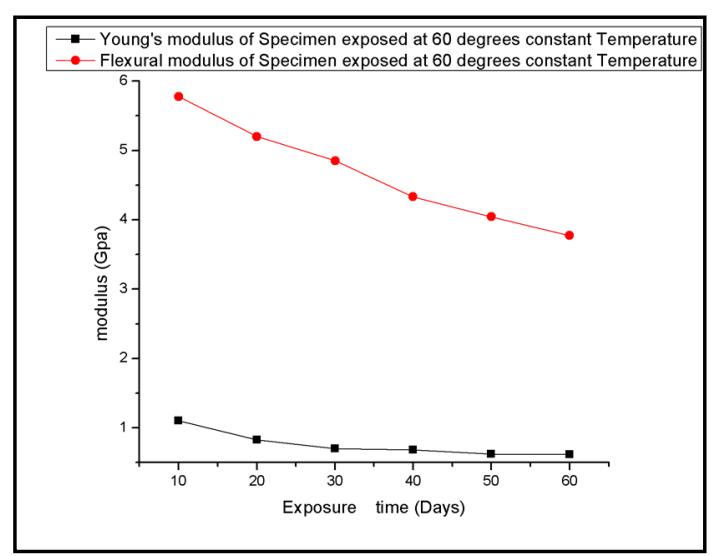

Graph 6. Modulus v/s Exposure time at constant temperature 600C

\section{Discussions}

The experimental results reveal that the GFRP (EGlass/Polyester) samples subjected to waters absorption at room temperature (results as shown in Graph5) the tensile modules has been rapidly reduced till 90 days and there a moderate reduction in it, whereas the flexural modulus has sharp reduction in the first 60 days and then a gradual reduction is observed. The samples subjected to aging at the constant temperature water bath $\left(60^{\circ} \mathrm{C}\right)$ showed a hyperbolic decrement in the tensile strength and the flexural modules (as shown in Graph6). On the whole it was observed that tensile modulus decreased to some extent with the presence of mo isture and temperature.

There is significant reduction in modulus because of loosing bonding strength of the polyester resin and fibre inter phase at room temperature. It is clear that the flexural modulus rapidly decreases with hydro aging and hydrothermal aging, because moisture generally affects any property which is dominated by the matrix and/or interface. However the flexural strength being a fibre dominated property the strength reduction occurs only if the fibres themselves are affected by hydrothermal environmental conditions..

The GFRP specimen showed a $66.7 \%$ reduction in the young's modules due to the increase in the water bath temperature, i.e., there is a considerable effect of the bath temperature on the mechanical properties of the GFRP composites.

\section{Conclusions}

From the investigation it is observed that there is a remarkable reduction in mechanical strength (young's and flexural modulus) is observed in GFRP composite laminates which are subjected to different environmental conditions a exposure time. The flexural strength values of the specimens are decreased with exposure period of 60days in water at constant temperature. As per the results initially rapid reduction in mechanical properties is observed and 
gradual decrease is observed during next phase.

The following important conclusions were drawn from test results.

a). The presence of moisture or water particles in the matrix, fibre-matrix interface and also attack on the glass fibres are all the reason for reduction of properties is due to interfacial bond damage.

b).The tensile and flexural modulus reduction is more in Hygrothermal aging when compare to hydro aging because the Temperature accelerated the aging processes

c).It is worth noticing that aging at higher temperatures caused colour change in samples.

e).The change in tensile properties of laminates during aging are due to of Hygrothermal degradation of glass fibre, matrix interface.

\section{REFERENCES}

[1] Arnold J.C., Environmental stress crack initiation in glassy polymers, Trends in Polymer Science 1996, 4, 403-408.

[2] Imielinska K., Acid-induced cracking of hybrid aramidglass/ep oxy composites, Proc. Conf. EDEM 2003, Bordeau

[3] KrystynaImielinska, Environmental stress cracking in eglass And aramid/glass epoxy composites, KOMPOZYTY (COMPOSITES) 6(2006)4

[4] Mechanical testing of advanced fiber composites J M
Hodgkinson Wood Head Publishing Limited.

[5] Springer G.S. Environmental effects on Composite materials Vol.2(1984),Lancaster PA:Technomic publishing co.inc.

[6] Dionysis E. Mouzakis Helen Zoga and Costas Galiotis "Accelerated environmental ageing studv of polyester/glass fiber reinforced composites (GFRPCs)-2007

[7] Environmental effects on bamboo-glass-polypropylene hybrid composites Moe MoeKinLiao 38 (2003) 363-376

[8] The "Durability of bamboo-glass fiber reinforced polymer matrix hybrid composites" by author MOE MOE THWE, KIN LIO publised in journal of Composites Science and Technology 63 (2003) 375-387

[9] The environmental stress corrosion cracking of glass fibrereinforced laminates and single E-glass filaments by author F.R.JONES. J.W.ROCK,J.E.BAILEY (19833)1059-1071

[10] Chin j.w.Nguyen.T and Aouadi.K (1997) "Effect of Environmental Exposure on Fiber-Reinforced Plastics (FRP) Materials Used in Construction" Journal of Composite Technology \&Research 19(4), 205-213.

[11] Wan B, Petrou MF, Harries KA. The effects of the presence of water on the durability of bond between CFRP and concrete. J Reinf Plast Composites 2006; 25(8):875-90.

[12] Q Qiu and M Kumosa 'Corrosion of E-glass fibers in acidic environments Composites Science and Technology, 199757 497-507

[13] C.Tukta and O.Buyukozturk on the "Deterioration of $\mathrm{FRP} /$ concrete bond system under variable moisture conditions quantified by fracture mechanic Composites: PartB 42(2011)145-154 Elsevier 